\title{
Los límites de la influencia de Carl Schmitt en la República de Weimar
}

\author{
JOSÉ LUIS VILLACAÑAS BERLANGA \\ Universidad de Murcia
}

RESUMEN. Este artículo expone los déficits de los juristas de izquierda de Weimar, Kirchheimer y Neumann a la hora de comprender la vida democrática y sus instituciones. La principal tesis de este ensayo es que estos déficits procedían de la influencia que el jurista conservador Carl Schmitt tuvo sobre ellos. Al depender de los argumentos que venían del que con el tiempo llegara a ser teórico de los nazis, los juristas de izquierdas se vieron incapaces de defender teóricamente la vida democrática.
Abstract. This article exposes the deficits that the left-wing jurists from Weimar, Kirchheimer and Neumann, showed when trying to comprehend the democratic life and its institutions. The main thesis defended in the article is that these deficits were result of the influence that the conservative jurist Carl Schmitt had on them. By introducing arguments coming from who later became a nazism's theorist, the left-wing jurists forund themselves disabled to theoretically defend democratic life.

\section{El Estado como Leviatán}

Para los juristas de izquierda, la base económica de la república de Weimar estaba caracterizada por el capitalismo monopolista. Todos ellos aceptaron la tesis de Pollock, según la cual el año 1929 significó el final del modelo competitivo o liberal del capitalismo. Esta nueva época reclamaba una mayor intervención del Estado. Sin embargo, este hecho no era un obstáculo para avanzar en la socialización de la vida. Al contrario, sin el Estado el nuevo capitalismo no era posible ${ }^{1}$. Ahora bien, la base social del Estado descansaba en mayorías de naturaleza proletaria. Así que todo estaba abierto a la acción política de las masas trabajadoras. Ésta es la tesis de Neumann en sus artículos iniciales, escritos hacia $1929^{2}$. Para él, este capitalismo monopolista tenía ante sí dos posibilidades en relación con el Estado: o una racionalización jurídica

\footnotetext{
1 «Los mercados ya no son libres, no se rigen naturalmente, sino por medio de leyes y relaciones de poder, y donde los derechos liberales como la propiedad privada, la libertad de empresa y de contrato han perdido su función». En «Über die Voraussetzungen und den Rechtsbegriff einer Wirtschaftsverfassung» de 1931. Ahora en A. Söllner (ed.), Wirtschaft, Staat, Demokratie. Aufsätze 1930-1954, Frankfurt, Suhrkamp, p. 79.

${ }^{2}$ Cf. «Gegen ein Gesetz über Nachprüfung der Verfgassungsmässigkeit von Reichsgesetzen», Die Gesellschaft, 1929, I, p. 521. Cf. igualmente «Die politische und soziale Bedeutung der arbeitsgerichtlichen Rechtsprechung», 1929, ahora en T. Ramm (ed.), Arbeitsrecht und Politik. Quellentexte. 1918-1933, Darmstadt, Luchterhand, 1966.
} 
amplia, en la que los grandes intereses de las corporaciones acordaran con los grandes sindicatos a través de una comprensión de la ley como disposición directiva; o un poder autoritario que defendiese a las corporaciones industriales de la presión creciente de las masas e impulsara una política unilateral. Era la creencia más básica de estos hombres que el primer proceso directivo sólo podría ser impulsado desde una política socialista. De esta idea se desprendieron cuando, al final de Weimar, Kirchheimer distinguió entre esfera directiva y esfera de distribución, tema central del que no podemos ocuparnos aquí.

Esta noción de Estado se basaba en la idea de la democracia como poder absoluto, por una parte, y del parlamento como sede de ese poder absoluto, por otra. En realidad, los enemigos hacia 1928 eran los jueces, que se desvinculaban de las indicaciones del poder político y se parapetaban en una noción de ley que bloqueaba la función política de la soberanía legislativa parlamentaria. Neumann decía en 1929 que «la constitución del Reich es la expresión de una democracia parlamentaria; esto es: de una forma constitucional en la que el parlamento es soberano, representa la voluntad del pueblo de forma absoluta y, por tanto, hace idénticos a dominadores y dominados. Una democracia absoluta semejante es inconciliable con el concepto de la división de poderes, y con la idea de la independencia judicial [...]. De hecho, el principal obstáculo organizativo para el poder del parlamento lo constituye actualmente la justicia» ${ }^{3}$.

Las leyes parlamentarias que Neumann tenía en mente hacia 1928 regulaban la economía y no alteraban la lista de derechos fundamentales. Acerca de ellas quizás nadie podía levantar la duda de constitucionalidad, por mucho que fuesen contra el sentido jurídico de la burocracia judicial. En cierto modo, es verdad que en cada sala se elevó su juez a tribunal constitucional. Con todo ello se trataba de impedir que el proletariado utilizase el poder legislativo de aquellas mayorías iniciales de la República. Desde luego, esta situación reflejaba la retirada de los poderes económicos de los pactos fundacionales de Weimar, endémica de la fase final de la república. Ni asociaciones empresariales, ni burocracias judiciales, como es sabido, querían seguir acordando con los sindicatos y los partidos una democracia económica y un Estado social. Frente al poder absoluto de la ley positiva emanada de un legislativo constitucional, las clases conservadoras esgrimieron la existencia de una ley natural de valencia supraconstitucional. Neumann era muy consciente de todos estos elementos. Pero no era menos cierto que ninguna teoría democrática constitucional permitía obviar la diferencia entre poder constituyente y poder constituido, y por mucho que se quisiera hacer del primero un poder absoluto, el segundo no podía serlo. Al no respetar esta diferencia, descubrimos en Neumann —y en los demás juristas - un elemento sintomático que debemos

3 «Die politische und soziale Bedeutung der arbeitsgerichtlichen Rechtsprechung», 1929, ahora en T. Ramm (ed.), Arbeitsrecht und Politik. Quellentexte. 1918-1933, Darmstadt, Luchterhand, 1966, pp. 115-116. 
interpretar. Sin reparar en él, no nos es posible comprender el gesto de Schmitt en 1932, cuando escribió Legitimität und Legalität. Al defender el carácter absoluto del poder del parlamento, Neumann no dejaba de considerar el Estado como un Leviatán, esto es, como un poder productor de homogeneidad social propiciando un autoritarismo de la legalidad.

En esta comprensión del Estado como Leviatán legislativo, Neumann unía dos aspectos. Primero, la necesidad de superar el liberalismo como ideología encubridora que usaba el Estado al servicio de una clase minoritaria. Segundo, la necesidad de comprender el Estado como una herramienta al servicio directo de los valores superiores de la justicia material. El Estado democrático asumía lo que de razón existía en el liberalismo y reconciliaba la forma del Estado con la libertad, la igualdad positiva y la justicia del iusnaturalismo ${ }^{4}$. Ésa era la idea del Estado social. No se trataba de igualdad ante la ley, sino de igualdad a través de la ley. Pero si esa ley tenía a su alcance la justicia material, como decía el art. 151.I de RV Weimar, ise trataba de una ley basada en una decisión parlamentaria normal, apoyada por mayorías y minorías constituidas? ¿O debía conectar en cada ocurrencia legislativa con el poder constituyente?

\section{La doctrina del Estado del socialismo y del bolchevismo}

Estas apreciaciones eran convergentes con las preguntas que inauguraban la habilitación de Kirchheimer de 1928. Éste también quería identificar el contenido posible de la dominación popular válida para el presente. En este sentido, Kirchheimer creía que lo propio de la democracia social era la exigencia de igualdad. Para él, socialismo era la democracia en sentido material. De forma consiguiente, reclamaba una unidad de valor - Werteinheit- que pusiera fin a la neutralidad del Estado liberal ${ }^{5}$. En cierto modo, consideraba que, sin esa coincidencia material de valores, un gobierno no podía legitimarse. Esa homogeneidad social, definida en relación con un valor unitario, legitimaba el poder legislativo soberano. Si se mantenía la neutralidad del Estado liberal, de hecho, el gobierno no podía reclamar obediencia para aquellas decisiones que dependieran de sus convicciones parciales y subjetivas. Sólo si el gobierno

\footnotetext{
${ }^{4}$ Cf. este texto: «Los derechos liberales pueden servir a todo partido político, a todo estamento, clase social, religión o comunidad para justificar su acción política. Cuando la estructura de esa comunidad se cubre con la ideología iusnaturalista - y éste es el caso del estado burgués de derecho- podemos hablar de una ideología expresiva. Por el contrario, si esa fundamentación iusnaturalista se contradice con el contenido espiritual de la comunidad - como es el caso de una democracia social - hablamos entonces de una ideología encubridora. En este contexto, esa justificación sirve para ocultar las ambiciones de poder de un grupo político», «Gegen ein Gesetz über Nachprüfung der Verfgassungsmässigkeit von Reichsgesetzen», Die Gesellschaft, 1929, I, p. 523.

${ }^{5}$ Cf. O. Kirchheimer, «Zur Staatslehre des Sozialismus und Bolchewismus», Von der Weimarer Republik: Die Auflösung der demokratischen Rechtsordnung. Hrsg. v. W. Luthardt. Frankfurt, Suhrkamp, pp. 33-34. Aquí se puede comprobar la crítica de Kirchheimer a Kelsen, en la forma clásica de Sozialismus und Staat.
} 
se vinculaba a convicciones objetivas, o a «representaciones de valor comunitarias» (gemeinsamen Wertvorstellungen) podría ser verdaderamente democrático y reclamar legitimidad. Una vez más, se trataba de la vieja implicación de legitimidad y protección de valores materiales. El parlamento, si obedecía a estos valores materiales, era una fuente legítima de legalidad.

Kirchheimer sabía que sólo la dependencia de valores materiales generaba legitimidad. Si debía existir democracia, estos valores materiales debían ser comunes y unitarios. De otra manera, no se generaba un juego válido de mayorías y minorías. La mayoría reclamaba obediencia sólo si impulsaba una variación de los mismos valores compartidos por las minorías, no si era una decisión dependiente de valores contrarios.

Pero al mismo tiempo, para estos teóricos, la sociedad se dividía en clases, dotadas de valores sociales y políticos heterogéneos. Cada decisión de clase estaba interpretada desde un cosmos intraducible al cosmos de la otra. El Estado liberal fue posible porque su ámbito de decisión era tan estrecho que no chocaba con representaciones de valores. Pero las funciones de administración en la sociedad avanzada rompían este Estado mínimo. Cargadas de contenidos, las decisiones del Estado ya no eran indiferentes. Interpretadas desde cosmos intraducibles, no hacían sino profundizar las diferencias de clases.

Los juristas de Weimar sabían que se encerraban en dos representaciones inicialmente contradictorias. Por una parte, veían las clases como realidades intraducibles. Por otra, se dieron cuenta, en la medida en que eran discípulos de Schmitt, de que el Estado no podía funcionar sin una mínima homogeneidad de base. Sólo esta homogeneidad daba la unidad material de valores para permitir el libre juego de mayorías y minorías. Esta homogeneidad estaba rota por la diferencia de clases. Sin embargo, jamás extrajeron la consecuencia ineludible: tenían que elegir entre lucha de clases y democracia política. Desde la lucha de clases, la única solución era conquistar el poder usando instrumentalmente el Estado como fuente de legalidad legitimada por un ideal de justicia material, superior en dignidad a la división de poderes. La otra opción era recomponer un comunitarismo de valores y desplegar un régimen democrático. Esto último sólo podía hacerse reduciendo la lucha de clases en algún modo.

Los juristas de Weimar mantuvieron ambas ideas como si fuesen compatibles. Afirmaron el Leviatán legislativo a favor de una clase y la necesidad de una homogeneidad social como base legítima de ese uso del Estado. En la misma página ${ }^{6}$ donde se cita a Schmitt, se critica la imposible neutralización jurídica del Estado, se denuncia la supuesta independencia de los jueces - en paralelo a Neumann-, se olvida el mecanismo jurídico-positivista, todas ellas falsas salidas de la época de la equipotencia de las fuerzas de clases (Gleichgewichts der Klassenskräfte), se describe la ineludible dualidad social amigo-enemigo de clase y se asume que sólo una homogeneidad democrática de valor

${ }^{6}$ Kirchheimer, «Zur Staatslehre des...», pp. 36-37. 
puede hacer dar forma al nuevo Estado. El problema era representarse esa homogeneidad democrática de valor compatible con la lucha de clases. Pues a Kirchheimer, como a Neumann, le parecía estéril la teoría del doble progreso, con su armonía preestablecida de avance material y refinamiento humano, con la que los socialdemócratas revisionistas, con Kautsky a la cabeza, pretendían escabullir el hecho de la violencia.

Así que, en el fondo, los juristas de izquierdas como Kirchheimer y Neumann eran discípulos a la vez de Marx y de Schmitt. Y esto sólo podía canalizarse por la mediación de Lenin, el único crítico de la humanista doctrina del doble progreso. Con su radicalismo teórico, Lenin rompió con una idea de moral o valor común a los grupos enfrentados en la lucha de clases. Pero a la vez afirmó la necesidad de crear una homogeneidad social radical. Kirchheimer, desde luego, leyó a Lenin desde Schmitt. Muy schmittiana resuena la tesis de que «esta lucha [leninista] es la que produce la verdadera agrupación de la humanidad». Con anterioridad a esa lucha no había humanidad unitaria. Mientras durara la lucha, tampoco. Lo que decidía la eticidad de los grupos era su posición en esta lucha. Bien ético era sólo la disposición a luchar por «la anulación de la sociedad antigua y la conquista del poder por el proletario». Eticidad era disciplina. Kirchheimer pensaba que estas ideas procedían de Sorel, y a su vez venían de Berdiaieff. El dualismo de Cristo y Anticristo estaba en su base, con una moralización ingente de la política. Ese nuevo mito del trabajador, el nuevo elegido, el nuevo purificado, constituía el poder creador. Pero Schmitt siempre estaba detrás, como lo demuestra esta conclusión de 1928: «El mito político posee la capacidad de provocar una agrupación política valorativa de naturaleza decisiva ${ }^{7}$. Se podía decir de otra manera: el mito era el poder propio del soberano, el politisches Formprinzip. Por decirlo pronto, la forma de escapar al dilema anterior era hacer de la homogeneidad la forma resultante de la victoria de uno de los grupos enfrentados. En el soberano, con su legitimidad material, estaba ínsita la razón de la homogeneidad futura construida con su valor. El mito era la predicación carismática de Weber que, por un error de cálculo, volvía a la vida, cuando todos pensaban que ya era imposible reencantar el mundo.

Kirchheimer es el más preciso testigo de que sin Lenin no se puede entender la comprensión que la izquierda tuvo de la República de Weimar. Además, Kirchheimer contempla a Lenin desde Schmitt. La dictadura bolchevique era el verdadero Estado de excepción, la verdadera dictadura soberana. Sólo esta teoría rompía, con la fuerza de la lucha, toda idea de tránsito orgánico desde la sociedad capitalista a la socialista. Esa dictadura ofrecía la precondición para crear la igualdad social del Estado socialista ${ }^{8}$. Las elecciones y los procedimiento democrático-formales, la legalidad en suma, no eran cosas valiosas

${ }^{7}$ Kirchheimer, «Zur Staatslehre des...», p. 43.

${ }^{8}$ Kirchheimer, «Zur Staatslehre des...», p. 45. 
por sí mismas, sino por el grado de enfrentamiento que procuraban y la justicia material que realizaban.

Desde esta perspectiva, la administración de justicia formal ya no podía reclamar independencia, sino que debía servir a los valores materiales de la sociedad socialista. La división de poderes era inviable. Las garantías jurídicas levantaban siempre obstáculos para la omnipotencia del soberano. El análisis de la constitución rusa mostraba que todo tenía un «valeur instrumental», que todo dependía de los fines socialistas. Estos fines materiales daban legitimidad a todo lo demás. Así que el derecho y la ley ya no aspiraban a ser universales, ni intemporales, sino particulares y temporales. Su justificación final era la aceleración de la muerte de esa época transitoria. Frente a los teóricos como Laski - el enemigo de Schmitt, y posterior maestro de Neumann-, que entendían llegado el momento de la desconstrucción (Abbau) del concepto de soberanía, el leninismo era una rehabilitación absoluta del concepto. De ahí su interna afinidad electiva con Schmitt. Por mucho que hubiese una imposibilidad teórica de precisar quién tenía la soberanía en la sociedad democrático-formal ${ }^{9}$, no quedaba duda de que en la URSS se había definido un Träger der Souveränität que tenía la schaliche Entscheidung im Konfliktfall $^{10}$. Lo novedoso de este nuevo Träger era que, por fin, separaba de forma rotunda soberanía y Estado. Más allá o más acá del Estado estaba el soberano verdadero: la clase. Por fin, el soberano aparecía como absoluto; no estaba vinculado a ley estatal alguna y «ella es universal según su tendencia». No sólo la clase designaba un soberano externo a los límites del Estado, sino que, con la política de intervención internacional ilimitada, se creaba algo superior a un Estado. De esta manera, el Estado socialista, para ser una herramienta flexible, necesitaba unificar el poder legislativo y ejecutivo y someter completamente el poder judicial. Ése era el sentido de la dictadura del proletariado.

Kirchheimer y Neumann pretendían mantener esta estructura política formal, pero canalizándola por el Leviatán legislativo. Frente a Lenin querían ser democráticos, y frente a Schmitt querían elevar el poder legislativo al poder absoluto y soberano. Ése era su margen de maniobra frente al positivismo, el liberalismo, el leninismo y el soberanismo carismático schmittiano. Este soberano democrático-social tenía que hacer legislativamente lo que la dictadura leninista hacía desde el comité central del partido. El problema era cómo lograrlo parlamentariamente en la época de la equipotencia de clases. Aquí se abría el obstáculo teórico básico. ¿Existía ya una unidad política unitaria, o más bien era cuestión de crearla mediante aquella decisión soberana? ¿Era

\footnotetext{
${ }^{9}$ Recuérdese la tesis de Laski de la «cooperative sovereignty», que en el fondo apelaba a un legislador social absolutamente imposible de descubrir, y que de hecho sólo tenía como traducción el reino autónomo de la economía. Cf. Laski, The problem of sovereignty. Authority in modern State, cf. la versión española El problema de la soberanía, Editorial Dédalo, trad. de Armando Bazán, Buenos Aires, 1960, p. 26-27.

${ }^{10}$ Cf. «Zur Staatslehre des...», p. 50.
} 
la homogeneidad causa o efecto del soberano? Por decirlo según categorías de Weber: iera el soberano autoritario o antiautoritario? Los juristas de izquierdas de Weimar no querían ser autoritarios. Creían que se daba ya la homogeneidad social y la identificaron con el proletariado, que podía expresarse como soberano absoluto en la mayoría parlamentaria. Leninismo de los fines con parlamentarismo de los medios, ¿acaso no era un absurdo teórico? ¿No era el componente autoritario inseparable a los dos teóricos sobre los que se basaba su construcción?

\section{Un diagnóstico sobre el origen de Weimar}

La forma de mediar estas contradicciones recuerda mucho al idealismo del Lukács de Historia y Conciencia de Clase. Aquí también Kirchheimer encontró la manera de unificar a Schmitt con autores marxistas. En diferentes escritos de la época, Kirchheimer defendía que las tensiones entre el ser y la voluntad eran frecuentes en una época de transición. Los rusos tenían una constitución que se basaba en campesinos y aspiraba por la voluntad a dotarse de una base proletaria. El papel constructor de la decisión constituyente soviética quedaba muy claro, en este sentido. De ahí derivaba su componente autoritario. Por su parte, a la estructura económica de Alemania le correspondía ya la constitución socialista. Si ésta no se había impuesto no era tanto por la presión de las potencias de la entente, cuanto por la falta de conciencia subjetiva del proletariado alemán, en un diagnóstico que podría proceder de Lukács ${ }^{11}$. Así que, finalmente, la estructura objetiva era socialista, pero la conciencia no. La homogeneidad social era proletaria, pero la homogeneidad política no era socialista. El idealismo de la tesis es claro: al no mediar entre el ser y la conciencia de manera oportuna, no había emergido la voluntad de realizar las posibilidades que ya estaban en el seno de la situación social objetiva. La clase obrera, la homogeneidad real, la unidad objetiva, era potencialmente soberana desde la estructura objetiva, aunque no lo era por voluntad. Así se había quedado indecisa la constitución de Weimar, porque el tránsito entre objetividad y subjetividad no se había dado. Ahí residía la esencia de la equipotencia de clases: una tenía a su favor la realidad social, la otra, la burguesa, la voluntad. Con ello se había organizado una democracia formal con base proletaria, al contrario de la constitución rusa. Una había sobrevalorado la voluntad y la otra la había perdido de vista. «Sólo nuestra voluntad abre el espacio a la constitución de la realidad socialista» ${ }^{12}$.

Kirchheimer echaba de menos que en 1920 se hubiese producido un gesto semejante a la constitución de 1793, impulsada por la interpretación radical-democrática y la expresión del querer popular. En Alemania, un pueblo cansado

\footnotetext{
${ }^{11}$ Cf. Kirchheimer, «Das Problem der Verfassung», en Von Weimarer Republik..., p. 66.

${ }^{12}$ Kirchheimer, «Das Problem der Verfassung», p. 68.
} 
no había tenido mito constructivo. Más allá de la voluntad de supervivencia alemana, no se había formado «una voluntad política comunitaria» ${ }^{13}$. La indecisión de la constitución de Weimar era de naturaleza histórico-filosófica: había permanecido entre la revolución de 1793 y la de 1918. No fue una Willensgemeinschaft, sino una Notgemeinschaft. No se empleó una Willensentscheidung y por eso las mayorías y minorías no podían jugar de manera constructiva ${ }^{14}$.

La idea que subyacía a Kirchheimer, y desde luego a Neumann, frente a Schmitt, era que el sujeto verdadero de la constitución alemana era el proletariado, no el pueblo alemán, mera forma sublimada de la voluntad burguesa. Esta idea la analizaba Kirchheimner en su ensayo Weimar, und was dann? Allí partía del supuesto de Rosa Luxemburg, según el cual «la actual constitución legal es meramente un producto de la revolución». Puesto que en el origen había una revolución, la única legalidad posible había de ser en la línea de esa misma revolución, venía a decir Luxemburg, en Sozialreform oder Revolution ${ }^{15}$. Por tanto, había una especie de legitimidad prestablecida en las medidas materiales que el legislador normal emprendiera en favor del proletariado, el verdadero sujeto de la constitución, y el único poder constituyente. La legalidad, siempre que fuera en esta dirección, era legítima. Esta idea era la que fundamentaba el Leviatán legislativo. La idea era que los verdaderos representados por el Estado eran los trabajadores y que el Estado en el fondo era la expresión universal de una estructura económica. Puesto que la ley era expresión universal, tenía que tener en su base una homogeneidad social. Puesto que la clave de distinción de esta sociedad era la economía, la homogeneidad social de base debía ser económica. En el fondo, la heterogeneidad de clases era una apariencia, algo que no tenía esencia objetiva propia, mero voluntarismo político que debía ser derrotado por la voluntad verdadera de los trabajadores. Lo único no aparente era la homogeneidad social proletaria, sólo que, desgraciadamente, no tenía suficiente voluntad.

Había aquí un diagnóstico sobre el origen de Weimar muy problemático. Kirchheimer era lo suficientemente realista como para reconocer que la monarquía había dejado de ser operativa no por un levantamiento popular, sino por obra del general Ludendorf, apoyado por la industria pesada ${ }^{16}$. Por lo demás, el propio Kirchheimer, en una reflexión ulterior, reconoció que si la burguesía entró en este juego fue con el fin concreto de lograr «la liberación externa de Alemania con los medios de una política pacífica de entendimiento» ${ }^{17}$. Los intereses y previsiones de las masas obreras eran muy distintas.

\footnotetext{
${ }^{13}$ Kirchheimer, «Verfassungswirklichkeit und politische Zukunft der Arbeitklasse», en Von der Weimarer Republik, p. 70.

${ }^{14}$ Es muy curioso hasta qué punto Kirchheimer y Neumann, en los artículos de 1929 ya hablan en pasado. Han descontado el final de Weimar.

${ }^{15}$ Kirchheimer, Politik und Verfassung, Suhrkamp, 1981, p. 9.

${ }^{16}$ Politik und Verfassung, pp. 10-11.

${ }^{17}$ «Artikel 48 und die Wandlungen des Verfassungssystems. Auch ein Beitrag zum Verfassungstag», en Von der Weimarer..., p. 91.
} 
Así, cuando se hizo el vacío, «para las masas revueltas no era suficiente una democratización de la constitución y aspiraban a una inmediata realización del socialismo» ${ }^{18}$. En el fondo, sabemos que esta tesis sobre el origen de Weimar nunca fue el dominante. Podemos decir entonces que en el fondo hubo como una especie de nostalgia de conquistar por la vía legal lo que Rosa Luxemburg no pudo conquistar por la revolución: superar la forma democrática burguesa. Pero esta nostalgia era fatal. Desde el principio, las formas de construir Weimar impedían la construcción de un estado socialista ${ }^{19}$.

El problema era más complejo. Kirchheimer se aproxima a la cuestión central cuando muestra la asimetría que conoció la evolución de Weimar, que de la estructura pactada de su origen, pasó a una amarga lucha entre los firmantes de los pactos. Pero sólo se aproxima al punto crucial. Él sugiere que, mientras que los empresarios consideraban que en los pactos ya habían entregado el máximo de sus concesiones, y así entendieron la política posterior como una aspiración a limitarlas al máximo, «los sindicatos vieron lo alcanzado como un comienzo pacífico y sin riesgos para la persecución de sus metas socialistas» ${ }^{20}$. Esta asimetría, sin embargo, no está correctamente descrita. Pues la clave estuvo en la propia comprensión del pacto. Nadie puede entender un pacto constituyente como punto de partida para conquistar las posiciones que no pueden ser aceptadas en el pacto. Éste era el fondo racional de la verdadera posición schmittiana, según la cual Weimar era una constitución sin decidir. Lo que realmente quería decir Schmitt era que Weimar no era una constitución. El pacto originario de Weimar se parecía más a un pacto de política exterior que a un pacto constituyente. La fuerzas pactantes firmaban una paz como punto de partida para llegar a posiciones que todos sabían que excedían los límites del pacto. No sólo las fuerzas conservadoras: también las fuerzas de izquierdas vieron aquel pacto como un principio de otra cosa. Nadie fue fiel al pacto. Lo que legitima un pacto constituyente es que excluye ciertas cosas, que decide dejar fuera determinadas posibilidades. Lo que quería decir Schmitt era que la constitución de Weimar no había sido capaz de eliminar de los firmantes su voluntad de tomar una decisión diferente en el futuro. La asimetría no era tal: ni empresarios ni sindicatos habían abandonado un ideal de llegada que sólo podría tomarse destruyendo el pacto. Por eso, era un pacto de política exterior, ya entre amigo y enemigo. Que unos quisiesen utilizar la legalidad y que otros empleasen la judicatura o el poder presidencial, era lo de menos. Lo que determinó la virulencia de la evolución, además, fue el hecho de que, mientras tanto, los antiguos pactantes fueron sustituidos en su hegemonía política. Así se tuvo pronto un pacto cuyos signatarios ya no eran políticamente dominantes.

\footnotetext{
${ }_{18}$ «Ahora bien, para las masas revolucionarias no se ha ido suficientemente lejos con la democratización de la constitución y aspiraban a una realización inmediata del socialismo».

${ }^{19}$ Kirchheimer, «Weimar und was dann?...», p. 13.

${ }^{20}$ Kirchheimer, «Weimar und was dann?...», p. 14.
} 


\section{Democracia y Decisión}

La cuestión estaba en el concepto mismo de democracia y en su evolución histórica. Aquí, Kirchheimer sabía que el problemas decisivo de la democracia, desde el siglo XIX, era el de impulsar la democracia nacional o política hacia la democracia social. Es muy importante esta progresión, porque permite a estos hombres recibir la influencia de Schmitt. Muy schmittiano de hecho era este pasaje: «El principio de la mayoría sólo es comprensible si se respeta la homogeneidad social, que en nuestra época viene representada por el principio de la comunidad de valor objetiva de la democracia. Sólo en una comunidad cuya estructura social es socialista la decisión mediante mayoría no significa una agresión violenta sobre los sometidos. Aquí la decisión de la mayoría sólo significa la aplicación de un medio experimentado de resolver conflictos relativos a la mejor realización técnica de todos los principios comunitarios» ${ }^{21}$. Sin embargo, la tesis schmittiana de la dimensión comunitaria de la democracia fue interpretada de forma incorrecta. Esta tesis reclamaba que la política la hiciera un grupo social existencialmente implicado. La existencia de esta unidad era condición de la verdadera política. Schmitt pensaba que tal unidad no existía con anterioridad a su activación por parte del soberano. Por eso, el soberano forjaba la comunidad como poder constituyente. Para estos socialistas, discípulos de Luxemburg, no eran así las cosas. El soberano, el poder constituyente, la homogeneidad social existía en la realidad económica de la clase. La decisión era transformar esta homogeneidad social en política. En sí misma, esta decisión no era para Kirchheimer sino la metamorfosis de la conciencia real en voluntad. Ya vimos que era la transformación de la clase en sí en la clase para sí. La diferencia entre Schmitt y los socialistas era que el primero confiaba en un soberano decisionista, mientras que los segundos confiaban en una política de masas, cotidiana y legal, con decisiones parlamentarias ${ }^{22}$. Obviamente, los últimos quedaron presos al intentar realizar con medios cotidianos una aspiración que era revolucionaria y autoritaria, como Schmitt sabía.

En la representación de los juristas de Weimar se daba una asimetría real en la comprensión de la democracia que resultó fatal. Para ellos, las fuerzas del socialismo estaban legitimadas a usar todos los mecanismos legales de la democracia para la construcción de una comunidad socialista. Las fuerzas burguesas no estaban legitimadas a usar todos los mecanismos legales para impedir esa posibilidad. Usar los mecanismos legales para realizar el socialismo era una operación de poner la democracia formal sobre la base de sus verdaderos contenidos materiales. Usar los mecanismos legales para impedir esta cons-

\footnotetext{
${ }^{21}$ «Weimar und was dann? Analyse einer Verfassung», en Politik und Verfassung, p. 17.

${ }^{22}$ Es muy iluminador para las relaciones entre Kirchheimer y Rosa Luxemburg un artículo tan tardío como "Marxismus, Diktatur und Organisationsform des Proletariats», en Fuktionen des Staats und der Verfassung. 10 Analysen, Suhrkamp, 1972, p. 100-114.
} 
trucción homogénea socialista era dictadura. Kirchheimer lo ha dicho claro: «Si el principio de mayoría es utilizado en la democracia política para impedir la realización de las exigencias sociales del proletariado, como en términos generales es hoy el caso, entonces estas democracias encierran en sí, a pesar de todas sus ocultaciones, un cuantum considerable de dictadura burguesa» ${ }^{23}$. Era cuestión de grados que esta dictadura burguesa se canalizara por el artículo 48, o por una más drástica suspensión de la constitución. En el fondo, los pensadores de izquierda jamás abandonaron la tesis de que la idea de su orden social, apoyado en la justicia, legitimada su actuación de una forma adicional a la legalidad de la forma democrática. Al imponer como condición de la democracia legítima la existencia de una homogeneidad social, no podían dejar de producir el efecto de que la democracia era una amenaza para las clases sociales heterogéneas con el proletariado. Desde ese punto de vista, consideraron la democracia formal como un paréntesis - como una Zwischenzeit- y esgrimieron la democracia proletaria fundada en una única homogeneidad social real, la de los trabajadores ${ }^{24}$. La diferencia residía en que las fuerzas conservadoras estaban dispuestas verdaderamente a canalizar un sentido autoritario de democracia a través del Presidente plebiscitario, mientras que las masas socialistas no podían utilizar esta opción. Las primeras sabían que sus ofertas eran electivamente afines con el autoritarismo. Las segundas, al pretender canalizarlas parlamentariamente, estaban internamente bloqueadas.

Toda la teoría de la decisión socialista - necesaria para estos discípulos de Schmitt - estaba lastrada por la teoría del reflejo. El parlamento era una escenificación de la lucha, pero no era la verdadera lucha. El parlamento no tenía un papel constructor de política, sino de reflejarla y hacerla evidente y observable. Esta reducción instrumental del parlamento a reflejo era muy marxista, como lo dejaba claro la habilitación de Kirchheimer ${ }^{25}$. Cuando éste señala que el parlamento no puede tomar decisiones políticas por sí mismo, sino que «sólo puede apoyar una voluntad política existente cuyo grado de intensidad se hace evidentemente observable en los resultados de las elecciones» ${ }^{26}$, estaba esperándolo todo de la categoría existencial de voluntad, claramente schmittiana. ¿Pero dónde estaba esta voluntad?

Los socialistas partían de una clase, de una idea social que no tenía una clara traducción política. Creaban así un enemigo políticamente activo antes de poner en marcha un sujeto políticamente activo. Creaba el enemigo antes de forjar el amigo. Para esta operación apelaban a formas variadas de espontaneidad de las masas. Schmitt no ponía condiciones sociales a su soberano:

\footnotetext{
${ }^{23}$ «Weimar...», p. 18.

${ }^{24}$ Cf. art. cit., p. 113. «Con ello la democracia proletaria fue tan cuestionada dentro del partido como lo fue la posibilidad de tránsito a las instituciones democráticas para las grandes masas del pueblo trabajador dentro del aparato del Estado mismo.»

${ }^{25}$ «Zur Staatslehre des Sozialismus und Bolschewismus», Von der Weimarer..., pp. 32 y ss.

${ }^{26}$ Op. cit., p. 25.
} 
la homogeneidad no tenía otro rostro que una unidad políticamente activa generada por un mito del presente. Creaba un enemigo, desde luego, pero también y a la vez una fuerza activa capaz de destruirlo. Esta diferencia entre homogeneidad política y social pasó desapercibida a los discípulos izquierdistas de Schmitt. Éste llevaba por delante la acción, y no apelaba a una voluntad misteriosa. Aquellos partían de la objetividad social, con la que condicionaban epistemológicamente el voluntarismo político de la clase. Con escepticismo, Kirchheimer ponía entre paréntesis, al hablar de la voluntad, «en el caso de que deba tener un sentido para las fuerzas del trabajo». Lo irrenunciable era el diagnóstico de que se trata de un dualistischen Klassenstaat ${ }^{27}$. Esta categoría era una abstracción política, pues no identificaba las fuerzas reales con las que se contaba. El organicismo político socialista, que anclaba el actor político en la realidad social de la clase, no había entendido la liberación schmittiana de la política respecto de la ordenación económica de las clases. Como era evidente, este movimiento de liberar la política de la economía interesaba a grupos sociales económicamente activos, pero Schmitt sabía que tenían la batalla perdida de representarse en términos de clases.

Pero si no se daba esa decisión, como voluntad adecuada al conocimiento, si el soporte sindical y proletario fallaba, entonces Weimar había puesto su supervivencia en manos de un ausente. En 1933, el ensayo sobre The Decay of German Democracy, ya hablaba en pasado acerca de la fuerza de los sindicatos, que tenían que hacer frente a una sociedad con 40 por 100 de paro. La inviabilidad de una democracia sin demócratas ya era evidente. Esto también se vio cuando Neumann contestó a Schmitt por el envío de su texto Legitimität und Legalität. Aquí, Neumann cambió de opinión en relación con su teoría del poder absoluto del legislativo. En una carta a Schmitt, Neumann echaba marcha atrás y reconocía que lo que había surgido como un compromiso, debía seguir siendo un compromiso. Puesto que se tenían que mantener las posibilidades de que el contrario llegase al poder, como clave de la justicia política, y puesto que el contrario era el trabajador para el empresario, resultaba claro que parlamentariamente no se podía disolver esta contraposición. El propio Neumann habló a favor de una solución plebiscitaria, aunque en sentido socialista.

¿Cuál fue para estos hombres la clave del fracaso de Weimar? Kirchheimer experimentó antes que Neumann la crisis de Weimar. En $1929^{28}$ ya sabía que

${ }^{27}$ «Weimar und was dann?...», op. cit., p. 28.

${ }^{28}$ Cf. este pasaje: «Actualmente puede considerarse fracasado el experimento que pretendía articular el socialismo en el aparato del Estado desde el punto de vista de la burguesía. Con él se ha demostrado que en el Estado democrático no se alcanza administrativamente el poder mediante la detentación de una cuota proporcional de los puestos gestores. Tan sólo la sustitución planificada desde abajo, y no desde arriba, del viejo cuerpo funcionarial por otro dominado por un nuevo espíritu puede proporcionar perspectivas de éxito a una política que mantenga la voluntad de avanzar en el socialismo. La mayoría de la PSD pretende evitar la toma de una decisión política global, tal y como lo exige la actual situación. Sin embargo, esa renuncia es imposible. 
ningún trabajador daría la vida por la República, pero que tampoco ninguno daría la vida por traer el socialismo. Desde luego, comprobaba así que la homogeneidad política nada tenía que ver con la teoría sociológica marxista. Tampoco tenía que ver con una homogeneidad ética. Para los socialistas, la única homogeneidad real sería aquella que entregara a los ciudadanos condiciones dignas y racionales, y sobre ella era preciso elaborar la democracia económica y política. El formalismo de la homogeneidad schmittiana apenas tenía nada que ver con todo esto ${ }^{29}$. Schmitt reclamaba una homogeneidad capaz de funcionar políticamente. Para eso no tenía que ser ya previamente, sino que existir forjada por el hombre carismático. La homogeneidad política de Schmitt era socialmente acósmica, como pronto demostraría el nazismo. Kirchheimer y Neumann apoyaban su política en una presunta homogeneidad social que, en el caso de que existiese, no sería afín con una extracotidianidad, ni con una dimensión acósmica, sino con una política normal y cotidiana, alejada del estado de excepción. Era la misma contradicción que elevar el parlamentarismo a dictadura legislativa. Schmitt, más sabio, no se aferró a ninguna homogeneidad prestablecida, sino a la que pudiera fundar la ruptura de un universo cotidiano. En el fondo, los socialistas estaban en un círculo vicioso: si la condición para operar era la homogeneidad política que no existía, y si el único sujeto que podía operar legítimamente era esa misma homogeneidad, entonces la parálisis era inevitable. De hecho, eso es lo que sucedió con los políticos de izquierdas, que ahí manifestaron su deuda final con la teoría del reflejo socialista. Schmitt, más nietzscheano, apeló a la decisión soberana de una voluntad de poder como aquella que funda homogeneidad, y no al revés.

En cierto modo, Kirchheimer vio claramente que la dominación burocrática era contraria al socialismo. Pero vio mejor aún que esa dominación burocrática, que dominaba la cotidianidad, era la mayor potencia frente a la predicación utópica socialista. Muy cerca del Weber que siempre acecha detrás de Schmitt, Kirchheimer echaba en cara al socialismo no tener una predicación carismática, no tener soberano capaz de tomar esa decisión. En el fondo, denunciaba la inexistencia de un espíritu propio capaz de cambiar de arriba abajo la burocracia.

Tan sólo se puede avanzar o retroceder. Pero para cobrar conciencia de ese avance debemos ante todo luchar, ya que todavía no hemos aprendido a elevarnos por encima de la cotidianidad. Hemos adorado la pura facticidad como si fuese el becerro de oro, convirtiéndonos así en esa clase de políticos realistas que construyen con el pasado un futuro cada vez más privado de expectativas. La utopía de hoy es la realidad del Mañana»; O. Kirchhcimer, «Verfassungswirklichkeit und politishce Zukunft der Arbeitklasse», op. cit., pp. 74-75.

${ }^{29}$ Colom, en su Las caras del Leviatán. Una lectura política de la teoría crítica, Barcelona, Anthropos, 1992, p. 109, n. 55, ha citado un pasaje de V. Neumann que dice: «Pese a la coincidencia teórica y metodológica, la divergencia de los intereses cognoscitivos de Schmitt y Kirchheimer es notable. Éste reconoce abiertamente el objeto de su interés: pretende colaborar responsablemente en la creación de condiciones sociales dignas y racionales. Resulta inútil buscar una declaración semejante en los escritos de Schmitt.» «Verfgassungstheorien politischer Antipoden: O. K. y C. S.», Kritische Justiz, 14, 1981, p. 238. 
Por mucho que Kirchheimer aceptara la diferencia entre parlamentarismo y democracia de Schmitt, por más que asumiera sus críticas ${ }^{30}$, mientras no hiciera valer lo que en el fondo hacía políticamente operativa la apelación schmittiana a la democracia, el soberano no ofrecía sino palabrería idealista. Esta dimensión suya chocaba abiertamente con el realismo de Schmitt. El socialismo de Weimar no tenía potencia alguna que oponer al vacío de soberanía en el sentido schmittiano. Por eso jugaba con una idea de homogeneidad que no era sino un dato estadístico, una constitución social, no una voluntad política. Ése era el punto de la sistemática de Schmitt que Kirchheimer no podía identificar en el campo proletario. Por decirlo con Weber, el problema era que la SPD era una estructura burocratizada diseñada especialmente para impedir la emergencia del líder político. Lo más trágico es que Kirchheimer lo supo desde el principio.

\section{Constitución sin decidir}

Kirchheimer podía haber iluminado la situación real de Weimar en la medida en que podía haber reclamado algo parecido a Schmitt, a saber: un soberano socialista autoritario. De hecho, que Weimar era una constitución sin decisión significaba claramente que no había encontrado todavía su soberano democrático-social. Como sabemos, Kirchheimer no consideraba la democracia como la posibilidad abierta a diferentes órdenes sociales y a distintas cosmovisiones ${ }^{31}$. Para él se trataba de definir un programa de contenidos democráticos afín con la forma democrática. En tanto que forma, la democracia reflejaba un orden social existente. En tanto que contenido, la democracia era un programa político único. Mientras que éste no se decidiera, no se había decidido nada. La burguesía estaba dispuesta a usar la forma para impedir la definición de ese programa. En realidad, había triunfado en esta intención.

Resulta fácil ver que esta diferencia entre forma y contenido reproducía las tensiones que venimos señalando. Si la forma reflejaba las relaciones sociales existente, y las elevaba a representación política, ¿cómo de ahí saldría un programa de acción que tuviese como finalidad «la organización de un nuevo orden social»? ${ }^{32}$. ¿Cómo el reflejo de un orden social iba a producir un programa que condujese a un nuevo orden social? Era evidente que la forma de la democracia, en el fondo, era algo más que una forma. Creaba agentes políticos que también se iban a resistir a desaparecer. Contra esta forma, que reflejaba voluntades diversas, el programa de contenidos sólo podía ser socialista. En

\footnotetext{
${ }^{30}$ «Mayoría parlamentaria y verdadero poder político pueden, pero no tienen que coincidir. Mayoría y poder son dos cosas distintas, y la mayoría en el parlamento es sólo una de las vías posibles, pero no absolutamente fiables, para conocer las verdaderas relaciones de poder.» Cf. «Bedeutungswandel des Parlamentarimus», Von der Weimarer..., p. 62.

${ }^{31}$ «Weimar und was dann?...», op. cit., p. 54.

${ }^{32}$ Op. cit., p. 54.
} 
el la forma democrática existente ya se debían reflejar políticamente las fuerzas suficientes para forjar ese nuevo orden social. En el fondo, Kirchheimer quería decir que en la época del sistema capitalista de las grandes corporaciones, las categorías formales de la democracia burguesa habían perdido su significado y que, justo por eso, habrían debido reflejar fuerzas políticas suficientes para tomar la decisión por el socialismo ${ }^{33}$. Pero él sabía que Weimar no se basaba ya sobre ningún reflejo de fuerzas políticas comprometidas con este socialismo. Esto se podía decir de muchas maneras, pero una de ellas fue sencillamente que la constitución se había levantado sobre una comunidad de emergencia (Notgemeinschaft) que ahora debía dotarse ante todo de continuidad. Para ello no se requería sino una fuerza política existente. El hecho decisivo es que esta comunidad, con su operatividad política, no podía descubrirse desde una estadística objetiva del pueblo, ni desde una estructura social objetiva: era un asunto de subjetividad, de operatividad, de fuerza.

Toda la cuestión estaba en que Schmitt sabía que su teoría albergaba dos elementos: una apelación a la democracia plebiscitaria, que en el fondo era una dictadura autoritaria así legitimada. Kirchheimer recogía el primer elemento, pero no podía asumir el segundo a no ser que quisiera ir al leninismo ${ }^{34}$, inviable en el movimiento obrero alemán. Se podía forjar poderes plebiscitarios, pero entonces no serían socialistas. Y se podía forjar poderes socialistas, pero no serían carismáticos, sino cotidianos. Así que bien mirado, lo lógico hubiera sido que los líderes del movimiento obrero hubieran renunciado a la retórica y se hubieran embarcado, con Frankel, en democratizar al máximo al presidente de la República, a forjar una unidad política efectiva del pueblo alemán, a garantizar una normalidad constitucional y a desarmar la opción autoritaria desde un consenso muy amplio. En cierto modo, en 1930, Kirchheimer sabía que el período constituyente había pasado, y con él la ilusión de la construcción del estado socialista. Cuando en su análisis del artículo 48 aludió a la necesidad de la autoconservación y la preservación del Estado, resultaba claro que ya se estaba a la defensiva. La defensa de la legalidad burguesa era en 1931 contraria a todo lo que Kirchheimer había aprendido de Schmitt y no reflejaba sino una posición desesperada. La legalidad burguesa ya estaba destruida, y apelar a ella era invocar un muerto.

Así que finalmente, la decisión que esperaba Kirchheimer no era sino la vieja socialdemocrática transformación de la objetividad de clase en voluntad de clase. Su mito era una espontaneidad que, en el fondo, era antimitológica.

${ }^{33}$ «Al final de la época burguesa, cuando pierden su contenido de sentido propio aquellas instituciones honorables como el Estado de derecho, la educación burguesa, la independencia judicial y la libertad de opinión, justo por las condiciones de vida específicas del sistema económico capitalista, la democracia sólo habría podido preservar para el socialismo un reconocimiento unívoco como principio de organización material de la sociedad», op. cit., p. 55.

${ }^{34}$ Ciertamente, Kirchheimer no quería ir allí, como lo demostró en su habilitación. Lo que no se dio cuenta es que Schmitt era un Lenin conservador y que sólo podía hacerle frente desde esta estructura de pensamiento. 
Todo esto desconocía la profunda lógica del pensamiento de Schmitt. Si para pasar de la forma democrática al programa democrático material se tenía que pasar de la objetividad social a la voluntad socialista, entonces era claro que tal metamorfosis nunca se daría. La decisión schmittiana era otra cosa: actuar autoritariamente y forjar la fuerza política de base popular, fuese cual fuese su reflejo social. Cuando Kirchheimer dejó de esperar esta decisión, que había de impulsar la imprescindible democracia material, se expresó de esta patética manera: «Fue el destino trágico de la constitución de Weimar que, en el momento de su nacimiento, no pudiese emerger en el proletariado alemán una fuerza de voluntad que habría cumplido aquella tarea de la creación de una democracia socialista, libre de todos los radicalismos verbales, pero con la disposición de hacer lo históricamente necesario» ${ }^{35}$. Lo que quería decir Kirchheimer era que la izquierda alemana no había sido leninista, ni había entendido la noción de voluntad a la manera de Lenin. Pero tampoco había encontrado a su soberano carismático, ni forzado una política extracotidiana, ni sabido desprenderse de la política socialdemocrática. Nadie había tenido la fuerza de pedir, exigir o producir políticamente el sacrificio de la clase burguesa. La fuerza política que finalmente reflejaba el orden económico y social no sólo no quería ese sacrificio, sino que deseaba restaurar una normalidad burguesa. Lo único terrible es que las burocracias de los partidos de izquierda decían querer otra cosa. Esta falta de honestidad política se pagó muy caro. Pues de haberse apostado por defender lo que de veras se quería, un orden burgués, quizás hubiera habido una salvación para Weimar.

Así que al final se impuso la necesidad de llegar a una reforma constitucional. Pero la dificultad estaba en la misma cuestión: ¿cómo se iba a hacer esa reforma si lo que estaba bloqueado era la propia operatividad del legislativo y del parlamento? Es más, ¿no había desprestigiado el propio Kirchheimer la forma parlamentaria de la democracia? Con todas sus letras había dicho que no era lo mismo democracia que parlamentarismo. Parlamentarismo era la clave de la forma burguesa de la democracia ${ }^{36}$. ¿Cómo iba ahora a invocarse la operatividad del parlamento para llevar adelante una reforma constitucional que hiciera efectiva la llamada «Esfera de la distribución»? La pregunta exigía una reflexión sobre política y capitalismo desarrollado que sentase otras premisas. Esa reflexión fue la que impulsaron nuestros autores en los últimos años de la época de Weimar. Era preciso buscar una política autónoma, pero finita, sin caer en el soberanismo decisionista absoluto de Schmitt. Ésa fue la tarea a la que se dedicaron estos hombres, entregándonos categorías sin lo que no es pensable lo que hoy entendemos como Estado de Bienestar.

\footnotetext{
${ }^{35}$ «Weimar und was dann?...», op. cit., p. 55.

${ }^{36} \mathrm{Cf}$. «Bedeutungswandel des parlamentarismus», Von der Weimarer..., p. 58.
} 